\title{
Software Quality Lessons from Medical Device Failure Data
}

\section{Dolores $\mathbf{R}$. Wallace \\ D. Richard Kuhn}

U.S. DEPARTMENT OF COMMERCE Technology Administration

Information Technology Laboratory

National Institute of Standards

and Technology

100 Bureau Drive

Gaithersburg, MD 20899 



\title{
Software Quality Lessons from Medical Device Failure Data
}

\section{Dolores R. Wallace D. Richard Kuhn}

\author{
U.S. DEPARTMENT OF COMMERCE \\ Technology Administration \\ Information Technology Laboratory \\ National Institute of Standards \\ and Technology \\ 100 Bureau Drive \\ Gaithersburg, MD 20899
}

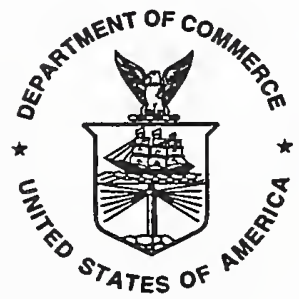

U.S. DEPARTMENT OF COMMERCE William M. Daley, Secretary

TECHNOLOGY ADMINISTRATION Gary R. Bachula, Acting Under Secretary for Technology

NATIONAL INSTITUTE OF STANDARDS AND TECHNOLOGY

Raymond G. Kammer, Director 



\begin{abstract}
Most complex systems todoy contain software, and systems failures activated by software faults can provide lessons for software development practices and software quality assurance. This presents an analysis of 342 software-related failures of medical devices that caused no death or injury but led to recalls by the manufacturers. The analysis categorizes the failures by their symptoms and faults. Tables provide methods for preventing and detecting the faults. The nature of the faults provides lessons about the value of generally accepted quality practices for prevention and detection methods applied prior to system release. It also provides some insight into the need for formal requirements specification and for improved testing of complex hardware-software systems.
\end{abstract}

Keywords: high assurance, medical devices, quality practices, software faults, system failures 
Table of Contents

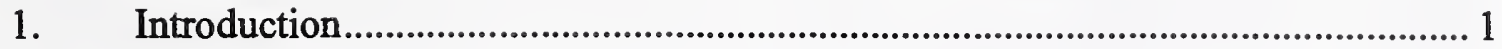

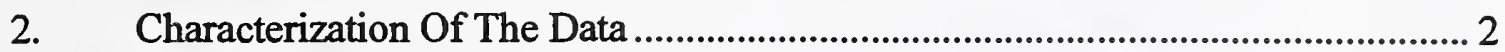

2.1 General Features of the Recall Data .................................................................... 3

2.2 Observed Behavior Signifying Need to Recall ........................................................... 4

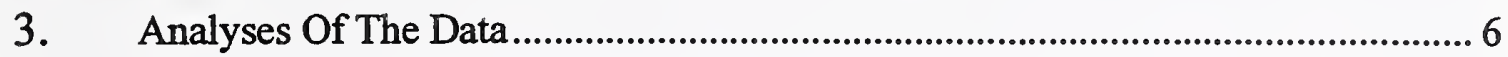

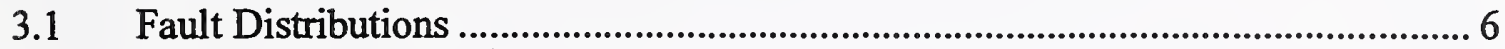

3.2 Prevention and Detection of Faults.............................................................. 8

3.2.1 Calculation...................................................................................................... 9

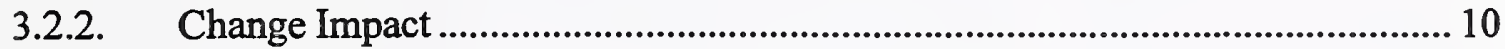

3.2.3 Configuration Management ............................................................................ 11

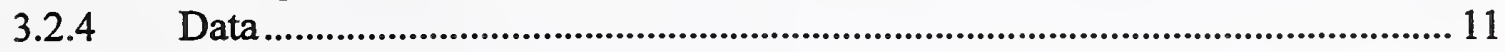

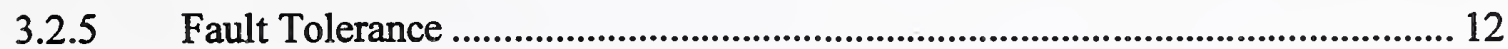

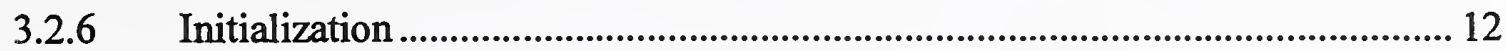

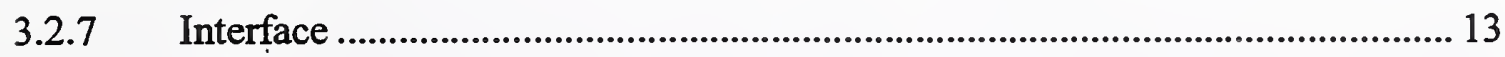

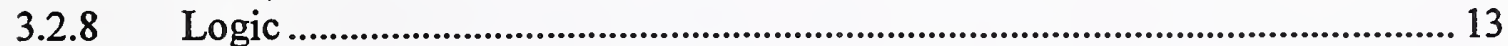

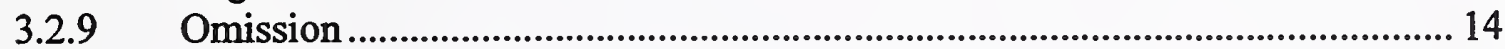

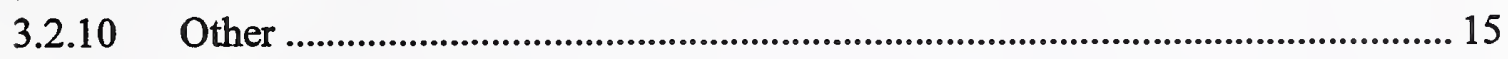

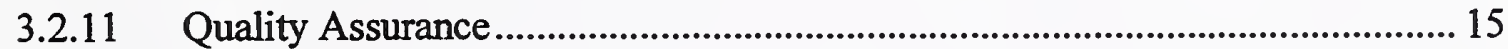

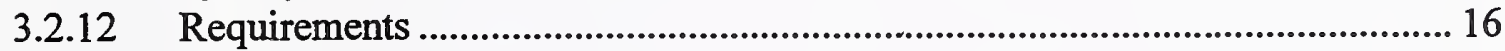

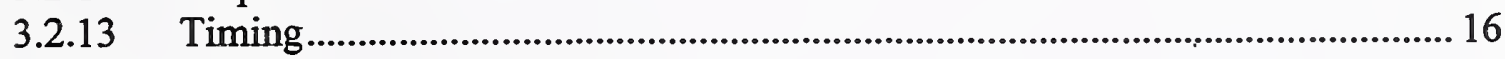

3.3 Testing Required for Detection of Errors ............................................................. 16

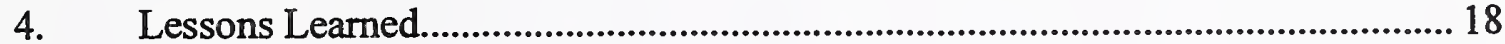

4.1 Development \& Maintenance ............................................................................ 18

4.2 Assurance Practices .............................................................................................. 19

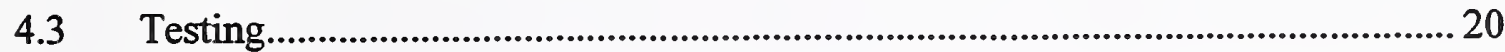

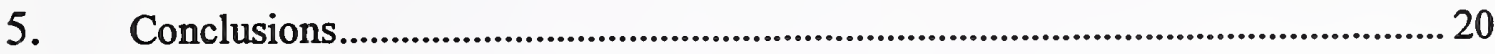

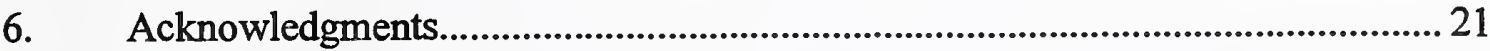

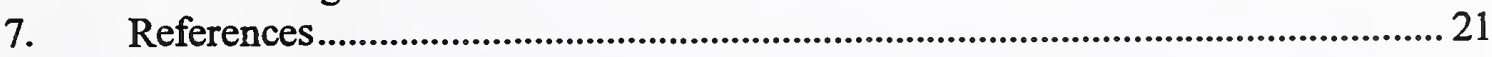

Table of Figures

Figure 2.1 Device type distribution.................................................................................. 4

Figure 2.2 Distribution of 383 failures by symptom ...................................................... 6

Figure $3.1 \quad$ Fault distribution......................................................................................... 8

Table of Tables

Table 1 Symptoms indicating device problems ................................................................. 5

Table 2 Partial list of detailed fault categories............................................................ 7

Table 3. Calculation faults .................................................................................. 10

Table 4. Change impact faults..................................................................................... 10

Table 5. Configuration management faults................................................................ 11

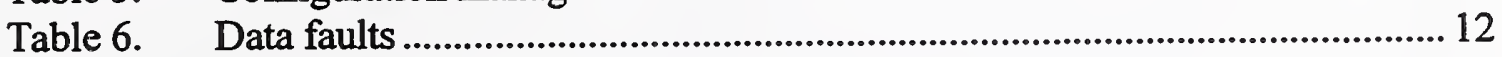

Table 7. Fault tolerance faults............................................................................... 12

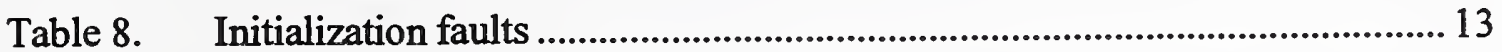

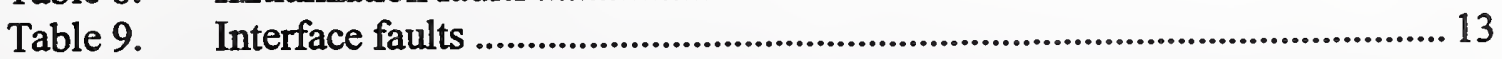

Table 10. Logic faults ................................................................................................. 14 


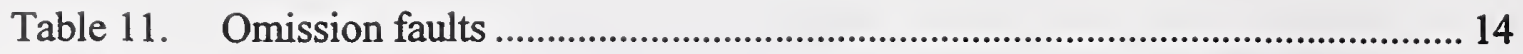

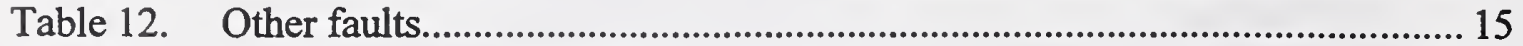

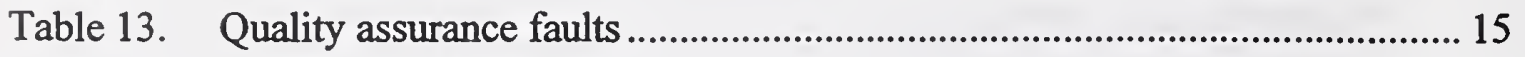

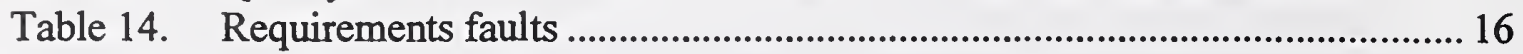

Table 15. Timing faults................................................................................................. 16 


\section{Introduction}

Software engineering is a relatively young discipline. It is very difficult to identify a set of "first principles" in software engineering, although at least one Delphi study" has attempted to gain consensus on software engineering principles. Older engineering disciplines are based on principles, including some learned from failures. Petroski devotes an entire book to lessons to be learned from failures in engineering [1]. In his preface, he states "the concept of failure - mechanical and structural failure in the context of this discussion - is central to understanding engineering, for engineering design has as its first and foremost objective the obviation of failure." He further states "the lessons learned from those disasters can do more to advance engineering knowledge than all the successful machines and structures in the world."

We take license in extending Petroski's beliefs about mechanical and structural engineering into the domain of failures of software systems. Lessons learned can either affirm proposed software engineering principles or help define new ones. Several industries, like telecommunications, space, business, and defense, were early drivers of computer technology. Within these industries, more and more features are controlled by, or executed with, software today than in the early years. While these industries have achieved great successes, they have also suffered embarrassing failures from which they have learned. We find a great need to examine software-based failures from many domains to gain insight about possible common causes of failures and the means to prevent them in the next system or, at the very least, to detect them before the system is released. The purpose is to reduce costs of systems by finding and detecting problems before such systems are recalled from multiple users. Loss of revenue from the customer and additional costs for fixing the system can become exorbitant.

Systems in all industries can fail for many reasons, including acts of nature, hardware failures, human error, vandalism and software. While the percentages of failures due to specific causes may differ by industry, most industries are vulnerable to most of the probable causes at some time or another. Our long-term objective is to study failure data from several industries individually and then in the aggregate, to identify the relationships to software problems. We have previously examined failures of the public switched telephone network [2].

Data about software system failures are not easy to locate. We have found a public collection of failure data on medical devices and focus our current examination on these system failures. Findings may apply to other application domains. Like most industries, the health care industry depends on computer technology to perform many of its functions, ranging from financial management and patient information to patient diagnosis and treatment. The use of software in some kinds of medical devices, while prevalent today, has become widespread only in the last two decades or so. ${ }^{2}$ We focus our

\footnotetext{
${ }^{1} \mathrm{http}: / /$ www.lrgl.uqam.ca/fpse/index.html

${ }^{2}$ From the lecture by Lynn Elliott, "When Safe Patients Means Dependable Software," in the Lecture Series on High Integrity Systems, U.S. National Institute Standards and Technology, October 1995.
} 
current study on medical devices that have been recalled by the manufacturers due to computer software problems. The Federal Food Drug \& Cosmetic Act defines a medical device as:

"an instrument, apparatus, implement, machine, contrivance, implant, in vitro, reagent, or other similar or related article, including a component part, or accessory which is:

- recognized in the official Formulary, or the United States Pharmacopoeia, or any supplement to them,

- intended for use in the diagnosis of disease or other conditions, or in the cure, mitigation, treatment, or prevention of disease, in man, or other animals, or

- intended to affect the structure or any function of the body of man or other animals, and which does not achieve any of its primary intended purposes through chemical action within or on the body of man or other animals and which is not dependent upon being metabolized for the achievement of any of its primary intended purposes."

The failures cited in this study were found in medical devices recalled by their manufacturers either in final testing, installation, or actual use. No deaths or serious injury resulted from these failures, nor was there sufficient information to estimate potential consequences had the systems remained in service. We are grateful to the Food and Drug Administration (FDA) for making these public data available to us in entirety. However we have conducted our own analyses and have drawn conclusions that do not necessarily reflect any analyses or conclusions by the FDA.

Using this FDA database of medical device failures, we examined the symptoms exhibited by the failures, identified the software faults that may have caused the problems, provided some generic guidance, and assessed what could have been done to prevent or detect the classes of faults. Section 2 contains a characterization of the system failure data, while Section 3 provides an analysis of the software faults, including an approach to testing multiple conditions. Section 4 contains a synopsis of the lessons learned with Section 5 providing conclusions about this study.

\section{Characterization of the Data}

A medical device may be as simple as a tongue depressor, but this report is concerned with those containing software in the categories of anesthesiology, cardiology, diagnostics, radiology, general hospital use, and surgery. These include such devices as insulin pumps, cardiac monitors, ultrasound imaging systems, chemistry analyzers, pacemakers, electrosurgical devices, anesthesia gas machines and many other types. The following highly simplified description is provided only to enable understanding of the classes selected for observed symptoms of malfunctions. A device is a system providing a service, involving one or more components. Some components may contain computer software, executing functions that produce an output either to the next function within a component or to another component of the system (e.g., a display device). The system behaves according to the values or messages it receives from the functions' output. An alarm may sound and / or the device may cease operation. A dosage rate or volume may 
change. Equipment may move. Measurements of various specimens or human reactions may be taken, and data may be recorded and associated with a patient's name. In general the failure was observed as a response of the physical system and not as an obvious software fault. Generally, the manufacturers needed to investigate to determine that the failure emanated from a software fault.

\subsection{General Features of the Recall Data}

The FDA data consist of the recall number, the product name, a problem description, and a cause description. The code for the recall number yields the year of the recall and the general type of device. Our purpose is simply to understand the types of software problems and to abstract some generic guidance about preventing and detecting the software faults before the systems are released for use. We recognize that over time manufacturers have improved their software processes and eliminated many factors contributing to these failures. Nonetheless we believe that learning from these recalls will reinforce the need for software quality practices and will help to provide specific guidance, especially to companies new to software development.

For the Fiscal Years 1983-1991, there were 2,792 quality problems that resulted in recalls of medical devices. Of those, 165 , or $6 \%$, were related to computer software. While the second group of data from 1992-1997 is not quite complete, the results are within the same ranges. We base our study on the software recalls. Of the total number (383) of software recalls from 1983-1997, 30 \% occurred in the years 1994 - 1996. One possibility for so high a percentage in three later years may be the rapid increase of software in medical devices. The amount of software in general consumer products is doubling every two to three years [3].

The recalls, or problems, can be grouped into classification panels relative to the primary function of the medical device. The medical devices fit into 7 panels: anesthesia, cardiology, general hospital use, in vitro diagnostics, radiology, surgery, or other. In vitro diagnostics includes chemistry, hematology, immunology, microbiology, pathology, and toxicology. Figure 2.1 shows the percentage distributions, where "other" includes anything else such as Obstetrics \& Gynecology or Ophthalmology for which there were not enough recalls to be grouped into their own panels. 


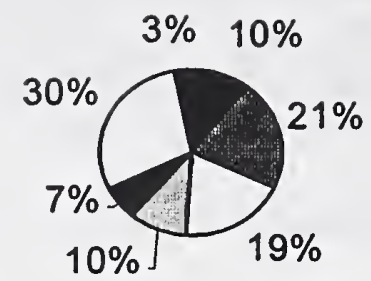

$\square$ Anesthesiology -10\%
Cardiology - $21 \%$
$\square$ Diagnostic - $19 \%$
$\square$ General Hospital -10\%
$\square$ Other - $7 \%$
$\square$ Radiology - 30\%
Surgery - 3\%

Figure 2.1 Device type distribution

\subsection{Observed Behavior Signifying Need to Recall}

The problem and cause descriptions contain information on which we base our analysis. They provide observations about the system or a feature, for example, the observed behavior may have been that an alarm failed to sound. Other observations concerned dosages that were too fast or too slow or were stopped inconsistent with the data on the display unit. Display unit values were inconsistent with other visual outputs of the device, for example, name of patient on screen not correct. The system simply stopped. The device performed in a manner completely unplanned, when several conditions occurred simultaneously. Data was lost or corrupted. In others, a calculation or other function was missing, or an instruction was omitted from the user manual. We simplified and abstracted from these descriptions generic information about behavior and probable fault types.

For each recall, we reduced the problem description to a few words about the symptom of its problem relative to a specific system attribute (e.g., behavior -- alarm did not sound; output -- incorrect relationship with display). Then we narrowed the list of symptoms to the key attribute and one description, such as behavior alarm. The result was a list of 37 symptoms (Table 1). The symptoms are specific to this set of medical device recalls and may not be observed in systems in other domains. 
Table 1. Symptoms indicating device problems

\begin{tabular}{|l|l|}
\hline Behavior alarm & Input reading \\
\hline Behavior dosage & Input: incorrect value accepted \\
\hline Behavior incorrect & Not validated \\
\hline Behavior unexpected & Output incorrect \\
\hline Data corruption & Output incorrect (radiation) \\
\hline Data loss & Output relationship \\
\hline Data loss; dosage & Output unobtainable \\
\hline Display incorrect & Quality \\
\hline Display relationship & Response incorrect \\
\hline Function failure & Service failure \\
\hline Function incomplete & Service frozen \\
\hline Function incorrect & Service not provided \\
\hline Function missing & Service not provided; alarm \\
\hline Function relationship & Service stopped \\
\hline Function unintended & Shut down \\
\hline Function unobtainable & System frozen \\
\hline General & Timing \\
\hline Input incorrect & User instruction \\
\hline Input incorrect relationship & \\
\hline
\end{tabular}

We reduced the long list of symptoms to the primary attribute groups in Figure 2.2; these may be applicable to various computer system domains:

- Behavior: the system performs an action due to some output of some function. The action is a physical action, e.g., movement of the gantry.

- Data: a consequence to the data, usually corruption or loss of input data.

- Display: the visual display on a screen -- numbers, text, or images in various formats.

- Function: usually a single calculation or activity; a software function in one module.

- General: not enough information to assign to a category.

- Input: the initial input (typed, sampled, read off equipment, database, file or tape, etc.) on which some operation is performed.

- Output: result of some function; generally an output to be used by the next function.

- Quality: user definition that "quality" not met.

- Response: something has happened that should not, e.g., power emitted above allowed amount; manifested in some hardware function.

- Service: greater than a single function -- a service of the system like pumping, ventilating, giving medication; generally involves more than one component (module, subsystem).

- System: the total system.

- Timing: timing of the instrument or a service of the device

- User instruction: manual, or other descriptions for the operator/ user.

These symptoms are similar to but differ somewhat from those in an IEEE standard addressing classification of faults[5]. One reason for this is to help us achieve our purposes in studying the behavior which is to enable understanding of the problem leading to identification of the underlying source of the fault that caused the problem. Another purpose is that if certain kinds of behavior are prevalent among recalled systems, 
then we suggest that test cases generated to force this behavior may help detect problems before systems are released.

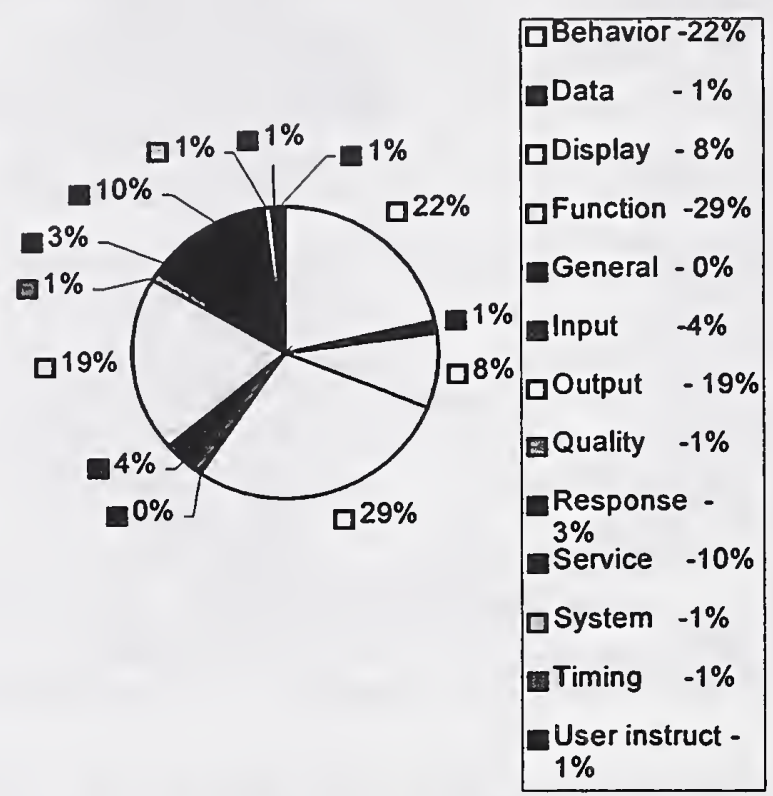

Figure 2.2 Distribution of $\mathbf{3 8 3}$ failures by symptom

\section{Analyses Of The Data}

The available information provides some insight about the nature of the failures of the medical devices, but the vendor did not always state the actual software fault. We had no mechanism for getting any further details, which sometimes meant we could not determine the cause of the problem. We tried to understand the nature and reason for occurrence of the software fault and to develop lessons regarding software quality practice. We derived the final fault class terminology from published taxonomies $[4,5]$ and reasoned how the various problems best fit, based on the problem and description as provided in the FDA database. ${ }^{3}$ From this limited information, we could discern the fault type for 342 failures. Only these 342 failures are discussed in the rest of this study.

\subsection{Fault Distributions}

We examined the software problem and cause descriptions to identify probable software fault types. In many cases there could have been 2 or 3 fault types contributing to a failure. Often study of the symptom revealed the generic nature of the fault. For example, the observed behavior may indicate that two or more events had occurred at their boundary values simultaneously, resulting in an incorrect or unexpected response.

\footnotetext{
${ }^{3}$ One of our lessons resulting from this study is that unless fault and failure descriptions are based on published classification systems, it is difficult to force the data into those classifications. While such classifications may fit during the actual fault discovery and resolution, they can only be used as guidelines for retrofit.
} 
Either the developers had not specified these events correctly in the requirements or the logic of the design or code failed to account for these simultaneous events. In the first case, the problem would be classified as a requirements problem (e.g., omission, ambiguity, conditions not considered) but the descriptions usually did not go to the source of the problem. Hence, we classified most of these as logic problems at the point of failure, although we recognize the value of better specification methods, specifically formal methods, in some of these situations and the prevalent belief that most faults are errors in the requirements specification. In Table 2 the primary fault type is shown first, followed by one or more specific problems related to it, for example, "rate" following "algorithm" indicates a function performed at a wrong rate in an algorithm.

Table 2. Partial list of detailed fault categories

\begin{tabular}{|l|l|l|}
\hline accuracy; rounding & Incorrect change to counting & Missing "allowed values" \\
\hline Algorithm; logic & Incorrect factor & Missing code \\
\hline Algorithm; rate & Incorrect logic to 2 conditions & Missing information in user manual \\
\hline Assignment & Increment; algorithm & not enough information \\
\hline Calculation; conditions & Increments; limits; delay factor & not validated; QA \\
\hline Calculation; factor & Initialization; data passing & Reinitialization \\
\hline Calculation; fault tolerance & input; data passing & Requirements; faulty formula \\
\hline change control; logic & Interface & ROM circuit \\
\hline change impact; QA & Interface; parameter value & Scaling \\
\hline CM; conditions & limits; calculation & Sequence of operations; QA \\
\hline $\begin{array}{l}\text { Conditions; wrong data } \\
\text { selected, passed }\end{array}$ & limits; change control & Switch; no recalculate \\
\hline COTS; memory lost; size & Logic; increment & Timing increment \\
\hline data passing; QA & Logic; initialization & Transposition \\
\hline fault tolerance & Loops; limits & Typo \\
\hline fault tolerance; logic & Maintenance removed feature & units, calculation \\
\hline improper impact of change & Memory; dead code & Volume \\
\hline
\end{tabular}

We reduced the number of fault categories to the final list in Figure 3.1, placing the detailed fault type into its "best fit" class. For example, "incorrect change to counting" was placed under "calculation" because the error occurred in the counting algorithm and did not cause additional problems that would have fit under "change impact." In Figure 3.1 , the pie wedges match the legend going clockwise, starting with calculation, near the top, at $24 \%$. 


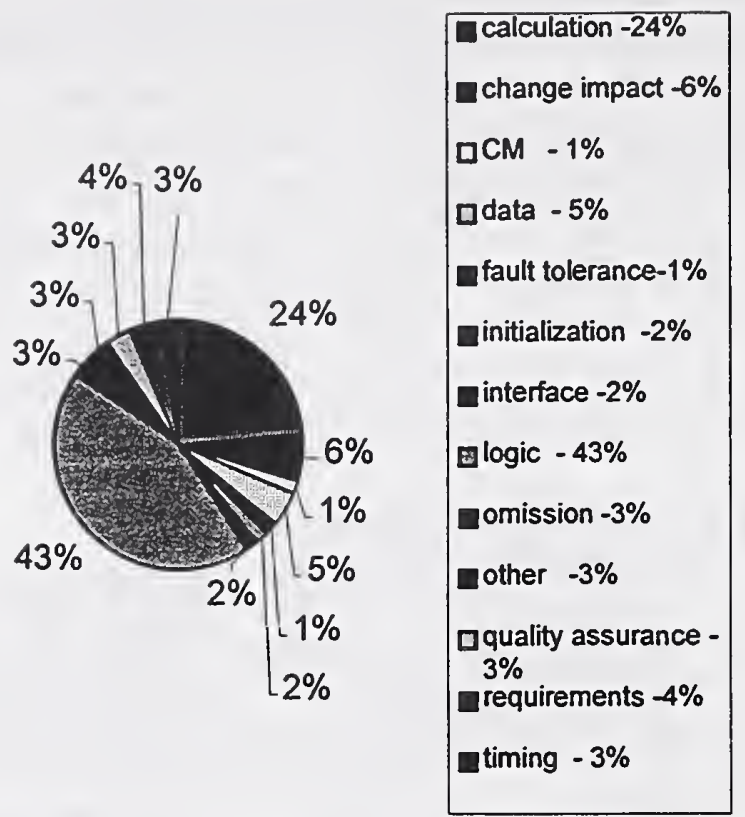

Figure 3.1 Fault distribution

Among the fault types, logic faults appear at $43 \%$. This category includes possible errors in logic in the requirement specification, unexpected behavior of two or more conditions occurring simultaneously, improper limits, and others that were more obviously stated in the "Cause" descriptions. The group "data" includes units, assigned values, or problems with the actual input data. The group "other" includes problems in COTS, EPROM, hardware, resources (e.g., memory), typos, and mistakes in translating requirements into code. For quality assurance, either the processes were not sufficient, or a new version was not validated.

The logic classification includes many fault types that with further details might have placed some of those faults into other classifications. The percentages for the logic and calculation faults generally remain high for each year. With the exception of 1995 , logic faults range from $30 \%$ to $60 \%$ for each year from 1985 on. Calculation is generally lower than logic, ranging from about $15 \%$ to $30 \%$ from 1985 on, but is consistently higher than the other fault types. These are low numbers relative to the 342 in the database, however. For 1996-7, calculation faults occur 9 times in radiology compared with 13 faults in all the panels. For logic, 4 faults for 1996 are in cardiology and 3 are in radiology out of 11 . Of 15 logic faults in 1997, 5 are in diagnostics, but 1 in radiology. The other fault classifications are smaller and vary over the years. While we could not directly answer the question "Why are logic and calculation the prevalent types?" we can provide guidance on preventing and detecting them before product release.

\subsection{Prevention and Detection of Faults}

These software recalls were distributed among 342 devices built by different vendors. What could have been done, individually, to prevent or detect each fault before the release of the device? We examined each fault in each of the thirteen classifications and 
attempted to determine an answer to this question. By prevent, we mean some method applied by the development group before testing. By detect, we mean some method of examination applied during testing or by quality assurance staff. ${ }^{4}$

Obviously we cannot ascertain whether these methods were used or not. We have no evidence that more experienced companies used these more than inexperienced companies. Rather, we can indicate perhaps an affirmation that these are best practices consistent with today's focus on process and need to be utilized[6]. The thirteen fault classifications contain 342 faults. First, for each fault, we considered various techniques/ methods for prevention, and then for detection. Next we reduced the results to a smaller, generic set for each fault classification. Some results appear in the following subsections; complete tables are available at http://hissa.nist.gov/effProject/handbook/failure.

Certain methods appear frequently in the synopses. We include inspection as both a prevention and detection technique, where inspection is used in a broader sense than the original Fagan inspection[7]. Glass nicely explains this broader view which is based on practitioners' presentations in workshops and conferences[8]. In the prevention approach, then, inspection may include code reading and various static analyses. Sometimes we were specific, because the fault description warranted more specificity. When inspection appears as a detection technique, then it generally means the traditional Fagan-type inspection.

\subsubsection{Calculation}

Many problems arise from issues regarding all types of calculations. Attention to algorithms and computations includes such details as verifying units, operators, intervals, limits, ranges, transformations from mathematical expressions into their implementation, and others. Sometimes even verifying that the original algorithm requirement is the correct version may be significant. Understanding how the specific computer will handle registers and floating point values is mandatory. Verifying all the issues for a calculation may require expertise outside computer science or software engineering. Often someone must verify that relationship between the algorithm and the intended use of its output is adequate, e.g., increments used in the algorithm will be useful in the displayed output (neither too large nor too small to be meaningful). The faults related to these issues are shown in Table 3.

\footnotetext{
${ }^{4}$ We are not promoting any specific project organization, but recognize that the development may perform all assurance activities or that a QA staff may conduct inspections and that testing may be conducted by the development group or by a separate testing staff.
} 
Table 3. Calculation faults

\begin{tabular}{|l|l|l|}
\hline Generic Problem & Prevention & Detection \\
\hline $\begin{array}{l}\text { Constants or table of constants } \\
\text { incorrectly coded. }\end{array}$ & $\begin{array}{l}\text { Design, code reading to ensure } \\
\text { correct relationship between the } \\
\text { specified constant or table and the } \\
\text { code. }\end{array}$ & $\begin{array}{l}\text { Code reading, inspection. Unit } \\
\text { test. }\end{array}$ \\
\hline $\begin{array}{l}\text { Improper handling of boundary } \\
\text { conditions (e.g. circumstances } \\
\text { close to limitation of the } \\
\text { operating environment). }\end{array}$ & Assertions - Fault tolerance. & $\begin{array}{l}\text { Focused inspections, code } \\
\text { reading or walkthrough. Unit test. }\end{array}$ \\
\hline $\begin{array}{l}\text { Improper handling of data } \\
\text { structure (array, bitset, list, queue, } \\
\text { set, stack, vector, etc.) }\end{array}$ & $\begin{array}{l}\text { Low level design review. Code } \\
\text { review. }\end{array}$ & $\begin{array}{l}\text { Code reading or walkthrough, } \\
\text { review, inspection. Unit test. }\end{array}$ \\
\hline $\begin{array}{l}\text { Precision problem (truncation or } \\
\text { rounding error during IO or } \\
\text { calculation). }\end{array}$ & $\begin{array}{l}\text { Low level design review. Code } \\
\text { review. }\end{array}$ & Code review. Unit test. \\
\hline $\begin{array}{l}\text { Improper handling of abnormal } \\
\text { conditions (e.g. wire disconnect } \\
\text { from the device, electrical noise). }\end{array}$ & Assertion. Fault tolerance. & Unit test. \\
\hline Graphical output meaningless. & $\begin{array}{l}\text { Review requirements for } \\
\text { relationship of computation } \\
\text { output to next function. }\end{array}$ & Interface test. \\
\hline Overflow. & Assertion. Fault tolerance. & Unit test. \\
\hline
\end{tabular}

\subsubsection{Change Impact}

While the impact of change is not necessarily considered a fault type, these cases indicate that lack of examining impact of changes hides other problems. In all cases, another practice, performing a traceability analysis, is a prerequisite for performing change impact analysis. The analyses identify the region the proposed change will affect. Table 4 shows some generic guidance on prevention and detection of faults related to these issues concerning fault found in the devices.

Table 4. Change impact faults

\begin{tabular}{|l|l|l|}
\hline Generic Problem & Prevention & Detection \\
\hline $\begin{array}{l}\text { Logic (incorrect conditions or } \\
\text { incompatibility with sequential } \\
\text { relationship) }\end{array}$ & $\begin{array}{l}\text { Traceability analysis. Change } \\
\text { impact analysis. }\end{array}$ & $\begin{array}{l}\text { Inspection of logic relative all } \\
\text { areas affected by change with } \\
\text { focus on original assumptions } \\
\text { (input values, selection criteria } \\
\text { for a function) }\end{array}$ \\
\hline $\begin{array}{l}\text { No verification against original } \\
\text { design specification }\end{array}$ & $\begin{array}{l}\text { Traceability analysis. Change } \\
\text { impact analysis }\end{array}$ & $\begin{array}{l}\text { Inspection of proposed changes. } \\
\text { Regression test }\end{array}$ \\
\hline $\begin{array}{l}\text { Loss of correct functions over } \\
\text { several upgrades; } \\
\text { Reversion to defect from at least } \\
\text { two version back }\end{array}$ & $\begin{array}{l}\text { Configuration management. } \\
\text { Change impact analysis }\end{array}$ & $\begin{array}{l}\text { Traceability analysis. Verification } \\
\text { against original specifications. } \\
\text { Interface test. }\end{array}$ \\
\hline $\begin{array}{l}\text { Incompatibility of changed } \\
\text { component with other } \\
\text { components }\end{array}$ & Configuration management. & $\begin{array}{l}\text { Inspection, assumptions of } \\
\text { relationships among components. }\end{array}$ \\
\hline Changes not validated & Daily quality practices. & Testing. \\
\hline
\end{tabular}




\subsubsection{Configuration Management}

For configuration management $(C M)$, that is, keeping all artifacts correctly associated with the appropriate version of the system, several problems may have been due to the incorrect exercise of $\mathrm{CM}$ procedures. Simply using $\mathrm{CM}$ may have prevented others. The use of tools to manage the software versions would be helpful. In some cases, the problems stem not from improper software versions, but from selecting a software program that is not compatible with the hardware. This is also a problem of requirement specification; once hardware and software configurations are selected, the assumptions about each component need to be recorded as part of the CM history. Table 5 describes typical CM faults.

Table 5. Configuration management faults

\begin{tabular}{|l|l|l|}
\hline Generic fault & Prevention & Detection \\
\hline $\begin{array}{l}\text { Incorrect configuration for non- } \\
\text { domestic systems }\end{array}$ & Use of CM tools. & $\begin{array}{l}\text { Verify usage of CM tools for all } \\
\text { changes. Verify configuration for } \\
\text { non-domestic use. }\end{array}$ \\
\hline $\begin{array}{l}\text { Software incompatible with other } \\
\text { components }\end{array}$ & $\begin{array}{l}\text { Record assumptions about all } \\
\text { components, in the CM data } \\
\text { component interfaces. CM } \\
\text { approval for configuring system } \\
\text { components }\end{array}$ \\
\hline $\begin{array}{l}\text { Failure to upgrade accompanying } \\
\text { system, to match software } \\
\text { changes }\end{array}$ & Traceability analysis. CM tools. & $\begin{array}{l}\text { Verification of changes; } \\
\text { regression test. }\end{array}$ \\
\hline $\begin{array}{l}\text { Use of wrong master program } \\
\text { when making software revision }\end{array}$ & Use of CM tools. & $\begin{array}{l}\text { Verification of appropriate master } \\
\text { program. CM manager releases } \\
\text { the versions. }\end{array}$ \\
\hline
\end{tabular}

\subsubsection{Data}

Problems in software programs arise from input data. The data requirements for the program must be specified, entered in the data dictionary, and validated before the operation using the data is executed. The specification includes information such as units, acceptable range of values, perhaps the expected quantity or frequency that values will change. These specifications need to be published in the data dictionary of the database and in the user instructions, with emphasis on values that could cause program stoppage if they are out of range. Of course, the program itself may address some potential problems by containing assertions for input values or input omission, with actions to take when data are incorrect or missing. When a program is fielded, data in a database should be protected by procedures to prevent database corruption. The software should facilitate an error-handling package to detect database corruption. Typical problems appear in Table 6. 
Table 6. Data faults

\begin{tabular}{|l|l|l|}
\hline Generic Problem & Prevention & Detection \\
\hline $\begin{array}{l}\text { System failed due to invalid input } \\
\text { data }\end{array}$ & $\begin{array}{l}\text { Assertions for invalid values, } \\
\text { checks for ranges that imply } \\
\text { incorrect data. Design: set criteria } \\
\text { of input data validation. Code: } \\
\text { implementation of input data } \\
\text { validation. }\end{array}$ & $\begin{array}{l}\text { Review for completeness of data } \\
\text { specification, and that all data } \\
\text { specifications are included in the } \\
\text { user instructions. } \\
\text { Inspection: focus on data } \\
\text { validation. Test against invalid } \\
\text { data. }\end{array}$ \\
\hline $\begin{array}{l}\text { Inconsistency of data retrieved } \\
\text { from database and that expected } \\
\text { by the program }\end{array}$ & $\begin{array}{l}\text { Assertions on validity of data } \\
\text { retrieved from database. }\end{array}$ & Testing focused on data retrieval . \\
\hline Database corruption & Database administration. & $\begin{array}{l}\text { Error handling routine in } \\
\text { software. }\end{array}$ \\
\hline
\end{tabular}

\subsubsection{Fault Tolerance}

The fault tolerance category relates to safety-critical systems that should include facilities to handle abnormal or anomalous conditions. Table 7 provides fault tolerance issues.

Table 7. Fault tolerance faults

\begin{tabular}{|l|l|l|}
\hline Generic Problem & Prevention & Detection \\
\hline $\begin{array}{l}\text { Excessive use of the program } \\
\text { causes failure }\end{array}$ & $\begin{array}{l}\text { Fault tolerance such as warnings } \\
\text { to operators. }\end{array}$ & $\begin{array}{l}\text { Stress/ volume test. Testing } \\
\text { against boundary and abnormal } \\
\text { conditions. }\end{array}$ \\
\hline $\begin{array}{l}\text { Incorrect action due to external } \\
\text { abnormal/ unexpected condition } \\
\text { related to power supply or other } \\
\text { components }\end{array}$ & $\begin{array}{l}\text { Fault tolerance. Software cannot } \\
\text { control abnormal condition } \\
\text { external to it, but can provide a } \\
\text { procedure in that event. } \\
\text { Requirement needs to be written } \\
\text { for FT. }\end{array}$ & $\begin{array}{l}\text { Test against boundary, abnormal, } \\
\text { and special conditions. } \\
\text { Exception handling routine in } \\
\text { software. }\end{array}$ \\
\hline $\begin{array}{l}\text { Incorrect action due to operator } \\
\text { error }\end{array}$ & $\begin{array}{l}\text { Fault tolerance in design through } \\
\text { code to protect against human } \\
\text { error. }\end{array}$ & $\begin{array}{l}\text { Inspect, review for protection } \\
\text { against operator error. Test } \\
\text { against unacceptable data entry. }\end{array}$ \\
\hline
\end{tabular}

\subsubsection{Initialization}

Initialization is essential for enabling programs either to begin or to perform more than one cycle of a function. Default values for variables are a necessity, and likewise, reinitialization of a variable must be established. Explicitly documenting the initial conditions in requirements through the code is essential. Code reviews, code reading need to focus on initialization. Table 8 describes initialization problems. 
Table 8. Initialization faults

\begin{tabular}{|l|l|l|}
\hline Generic Problem & Prevention & Detection \\
\hline $\begin{array}{l}\text { Lack of initialization of the } \\
\text { runtime environment while the } \\
\text { program initially executes or } \\
\text { restarts }\end{array}$ & $\begin{array}{l}\text { Use assertions for initialization. } \\
\text { For C or C++, see } \\
\text { http://hissa.ncsl.nist.gov/effProjec } \\
\text { t/handbook/c++/variables.htm }\end{array}$ & $\begin{array}{l}\text { Inspections; Code review. Test } \\
\text { against initial conditions. }\end{array}$ \\
\hline $\begin{array}{l}\text { When the program executes first } \\
\text { time, it fails to store necessary } \\
\text { initialization values for the } \\
\text { succeeding run. }\end{array}$ & $\begin{array}{l}\text { Document initial conditions for } \\
\text { both initial run and consecutive } \\
\text { run. Design review. }\end{array}$ & $\begin{array}{l}\text { Code review. Stress test (run the } \\
\text { program multiple times). }\end{array}$ \\
\hline
\end{tabular}

\subsubsection{Interface}

In a system, software often will send data, that is, interface, to physical components of the system, as well as between software modules and to users. Clearly, the requirement specification must be accurate, complete, and consistent. A traceability scheme provides a basis for ensuring that all interfaces are included correctly. A well-developed test plan for integration test must be executed to verify the proper interface between devices or software components. Table 9 describes interface problems.

Table 9. Interface faults

\begin{tabular}{|l|l|l|}
\hline Generic Problem & Prevention & Detection \\
\hline $\begin{array}{l}\text { Software does not properly } \\
\text { interface with external device or } \\
\text { other software component. }\end{array}$ & $\begin{array}{l}\text { Trace requirements through } \\
\text { design through code to ensure all } \\
\text { software functions have } \\
\text { interfaces to either another } \\
\text { software module or to an output } \\
\text { device or other system } \\
\text { component or user. Examine the } \\
\text { specification for each interface. }\end{array}$ & $\begin{array}{l}\text { Inspections, reviews } \\
\text { Integration test. }\end{array}$ \\
\hline
\end{tabular}

\subsubsection{Logic}

Logic problems appear to be significant. While some failures of the devices did result from bad logic, the "bad" logic might have resulted from incorrect, incomplete, or inconsistent requirements or designs. Frequently, interactions among different functions might not have been considered at all or might have been neglected at boundary conditions of a function. Sometimes the logic might have been incorrect in the design. All of these were classified as logic problems, but it should be understood that the source of the problem could have been requirements, design, or code. While Table 10 describes some logic problems, other examples in the logic classification include problems like these: 1) "When power lost and then restored, system defaults to off status, which causes false information to operator and possible hazard to the operator" and 2) "When a second cartridge is in the other slot and detects an artifact condition, the monitor is prevented from alarming below set levels." 
Table 10. Logic faults

\begin{tabular}{|l|l|l|}
\hline Generic Problem & Prevention & Detection \\
\hline $\begin{array}{l}\text { Incomplete or incorrect control } \\
\text { logic }\end{array}$ & $\begin{array}{l}\text { Design review. Walk through the } \\
\text { software implementation against } \\
\text { design. }\end{array}$ & $\begin{array}{l}\text { Code Review. Inspection. } \\
\text { Testing. }\end{array}$ \\
\hline $\begin{array}{l}\text { Configuration scheme for } \\
\text { component interaction allows } \\
\text { incorrect behavior. }\end{array}$ & $\begin{array}{l}\text { Modeling. Simulation. Formal } \\
\text { methods. }\end{array}$ & $\begin{array}{l}\text { Code review. Interface analysis. } \\
\text { Integration test. System test. }\end{array}$ \\
\hline $\begin{array}{l}\text { Improper handling of boundary } \\
\text { conditions. (e.g. limits of value } \\
\text { range) }\end{array}$ & $\begin{array}{l}\text { Design review. Verify logic for } \\
\text { all conditions, esp. at boundaries. } \\
\text { Fault tolerance. Code review. }\end{array}$ & $\begin{array}{l}\text { Code review. Inspection; Test } \\
\text { against boundary and abnormal } \\
\text { conditions. }\end{array}$ \\
\hline $\begin{array}{l}\text { Improperly handle abnormal or } \\
\text { exceptional (e.g. power lost, } \\
\text { multiple inoperative conditions } \\
\text { occurred, VO interrupt, VO error, } \\
\text { etc.) }\end{array}$ & $\begin{array}{l}\text { Design review. Assertion. Fault } \\
\text { tolerance. Review error recovery } \\
\text { routines. Code review. }\end{array}$ & $\begin{array}{l}\text { Code review. Inspection; Test } \\
\text { against abnormal and exceptional } \\
\text { conditions. }\end{array}$ \\
\hline $\begin{array}{l}\text { Improper data validation. (e.g. } \\
\text { input or output data out of range) }\end{array}$ & $\begin{array}{l}\text { Design review. Walk through the } \\
\text { software implementation against } \\
\text { design. Verify logic for data out } \\
\text { of limits. }\end{array}$ & $\begin{array}{l}\text { Code review. Inspection; Test } \\
\text { against I/O boundary conditions. }\end{array}$ \\
\hline $\begin{array}{l}\text { Programming error (e.g. error in } \\
\text { pointer, addressing, looping, } \\
\text { indexing, subscript, memory } \\
\text { management, etc.) }\end{array}$ & $\begin{array}{l}\text { Low level design review. Code } \\
\text { review. }\end{array}$ & Code review. Unit test. \\
\hline
\end{tabular}

\subsubsection{Omission}

Examples of omission in Table 11 show that systems were delivered without all necessary pieces or documentation. Some required system functions are missing from the final implementation. The documentation is missing or not sufficient to install or operate the product.

Table 11. Omission faults

\begin{tabular}{|l|l|l|}
\hline Generic Problem & Prevention & Detection \\
\hline Vital system functions are & $\begin{array}{l}\text { Trace requirements through } \\
\text { design through code, focus on all } \\
\text { interfaces. Trace into user and } \\
\text { test documentation. Use critical } \\
\text { path analysis to ensure } \\
\text { completion. Prepare system test } \\
\text { scenarios at requirements } \\
\text { specification and examine them } \\
\text { for relationship to trace through } \\
\text { code. }\end{array}$ & $\begin{array}{l}\text { Inspections, reviews examining } \\
\text { traceability of functions. } \\
\text { System Test. }\end{array}$ \\
\hline $\begin{array}{l}\text { Lack of documentation, or } \\
\text { improper documentation. }\end{array}$ & $\begin{array}{l}\text { Proper release procedure. } \\
\text { Traceability. }\end{array}$ & $\begin{array}{l}\text { Verify completeness by } \\
\text { examining trace. Inspection. }\end{array}$ \\
\hline
\end{tabular}




\subsubsection{Other}

Faults that cannot be classified into the categories specified in this report and were too low in frequency to be a category are included in Table 12 for other faults. They include problems such as performance issues, $\mathrm{I} / \mathrm{O}$ problems, typographic error in code.

\section{Table 12. Other faults}

\begin{tabular}{|l|l|l|}
\hline Generic Problem & Prevention & Detection \\
\hline $\begin{array}{l}\text { Out of compliance with the } \\
\text { performance standard. }\end{array}$ & $\begin{array}{l}\text { Simulation. Design review. Code } \\
\text { review. }\end{array}$ & Performance test. \\
\hline $\begin{array}{l}\text { Calculations associated with the } \\
\text { "\%" activity curve have been } \\
\text { printed incorrectly. Formatting } \\
\text { subroutine for screen display. }\end{array}$ & $\begin{array}{l}\text { Code review: review special IOO } \\
\text { routine. Understand the } \\
\text { hardware/software requirements } \\
\text { of the display system. }\end{array}$ & $\begin{array}{l}\text { Unit testing with focus on } \\
\text { verifying output against internal } \\
\text { calculations. }\end{array}$ \\
\hline $\begin{array}{l}\text { A typographic error in software } \\
\text { algorithm causes incompatibility } \\
\text { between two devices. }\end{array}$ & $\begin{array}{l}\text { Code reading against algorithm } \\
\text { specifications. }\end{array}$ & $\begin{array}{l}\text { Walkthrough focussed on } \\
\text { algorithms. Testing. }\end{array}$ \\
\hline
\end{tabular}

\subsubsection{Quality Assurance}

The role of quality assurance is to ensure that quality practices are defined and are implemented. Procedures, requirements for quality need to be contained in company standards, which project management or a quality assurance group must ensure get used. Procedures for validation after modifications are necessary. The problems described in the recall data often cite that process checks were not made on the testing process and that testing was not performed after modifications. The problem descriptions do not reveal whether procedures for testing or other quality practices had been defined. Change impact analysis is a key task to ensure appropriate tests after modifications. While QA is not a fault type, it is a process problem whose use may have prevented some of the failures. For this category, prevention techniques refer to discovering problems with QA. The responsibility for quality belongs to everyone on the project. Table 13 provides more information about quality assurance problems.

Table 13. Quality assurance faults

\begin{tabular}{|l|l|l|}
\hline Generic Problem & Prevention & Detection \\
\hline $\begin{array}{l}\text { Test plan was not implemented or } \\
\text { executed appropriately. }\end{array}$ & $\begin{array}{l}\text { Software project management } \\
\text { oversight. }\end{array}$ & $\begin{array}{l}\text { Project status review. } \\
\text { QA process checks. }\end{array}$ \\
\hline $\begin{array}{l}\text { Regression test was not } \\
\text { performed on modified software. }\end{array}$ & $\begin{array}{l}\text { Software project management } \\
\text { oversight. } \\
\text { Change impact analysis. }\end{array}$ & $\begin{array}{l}\text { Project status review. } \\
\text { QA process checks. }\end{array}$ \\
\hline $\begin{array}{l}\text { No validation before initial } \\
\text { release. }\end{array}$ & $\begin{array}{l}\text { Specified procedures regarding } \\
\text { testing before product release. } \\
\text { Software project management } \\
\text { oversight. }\end{array}$ & $\begin{array}{l}\text { Project status review. } \\
\text { QA process checks. }\end{array}$ \\
\hline $\begin{array}{l}\text { No validation on software } \\
\text { changes. }\end{array}$ & Software project management. & $\begin{array}{l}\text { Project status review. } \\
\text { QA process checks. }\end{array}$ \\
\hline
\end{tabular}




\subsubsection{Requirements}

Some faults, such as omission, logic, and calculation, may have their genesis in the requirements specification. This category, shown in Table 14, demonstrates the need to develop, verify and validate a requirement specification, in some cases uses formal methods. The document specifying the product requirements is critical to the completeness and correctness of the software of the final product. The review of the requirements may require experts with different types of expertise to ensure that the requirements call for the right functions, appropriate algorithms, correct interfaces, function interaction, and other aspects.

Table 14. Requirements faults

\begin{tabular}{|c|c|c|}
\hline Generic Problem & Prevention & Detection \\
\hline $\begin{array}{l}\text { Exceptional conditions were not } \\
\text { specified in the requirement } \\
\text { specification. }\end{array}$ & Modeling. Analysis. Traceability & $\begin{array}{l}\text { Interface analysis. } \\
\text { Requirement review. System test. }\end{array}$ \\
\hline $\begin{array}{l}\text { Functions missing in the } \\
\text { requirement specification. }\end{array}$ & Modeling. Analysis. Traceability. & $\begin{array}{l}\text { Interface analysis. } \\
\text { Requirement review. System } \\
\text { test. }\end{array}$ \\
\hline $\begin{array}{l}\text { Requirement specification was } \\
\text { incorrect for its usage with other } \\
\text { components. }\end{array}$ & $\begin{array}{l}\text { Modeling. Interface Analysis. } \\
\text { Traceability. }\end{array}$ & $\begin{array}{l}\text { Requirement review. Interface } \\
\text { analysis. } \\
\text { Design review. } \\
\text { System test. }\end{array}$ \\
\hline $\begin{array}{l}\text { Test hooks or monitors were not } \\
\text { specified }\end{array}$ & $\begin{array}{l}\text { Requirement review. Design } \\
\text { review. }\end{array}$ & Integration, system test. \\
\hline
\end{tabular}

\subsubsection{Timing}

Timing is vital to the execution of real-time applications. Processes that are interacting in real time must be completely synchronized. Table 15 provides examples.

Table 15. Timing faults

\begin{tabular}{|l|l|l|}
\hline Generic Problem & Prevention & Detection \\
\hline $\begin{array}{l}\text { Two inter-react processes are out } \\
\text { of time synch with one another }\end{array}$ & $\begin{array}{l}\text { Simulation. Design review. Code } \\
\text { review. }\end{array}$ & Timing analysis. Integration test. \\
\hline Real time clock was not accurate. & $\begin{array}{l}\text { High quality real time operating } \\
\text { system. Fault tolerance }\end{array}$ & Timing analysis. System test. \\
\hline $\begin{array}{l}\text { Scheduled event did not occur } \\
\text { due to timer failure. }\end{array}$ & $\begin{array}{l}\text { High quality real time operating } \\
\text { system. Fault tolerance }\end{array}$ & Timing analysis. System test. \\
\hline
\end{tabular}

\subsection{Testing Required for Detection of Errors}

How good is software testing in the medical device industry? One way to study this question is to look at what conditions are required to trigger the faults that remained after release. That is, is the fault manifested in a single condition, or two or more conditions? 
Some of the failure s (109 out of the complete set of 342) contained sufficient detail to determine what level of testing would be required to detect the fault. For example, one problem indicated that "if device is used with old electrodes, an error message will display, instead of an equipment alert." In this case, testing the device with old electrodes would have detected the problem. Another indicated that "upper limit $\mathrm{CO} 2$ alarm can be manually set above upper limit without alarm sounding." Again, a single test input that exceeded the upper limit would have detected the fault.

Other problems were not so easily manifested. One noted that "if a bolus delivery is made while pumps are operating in the body weight mode, the middle LCD fails to display a continual update." In this case, detection would have required a test with the particular pair of conditions that caused the failure: bolus delivery while in body weight mode. One vendor's description of a failure manifested on a particular pair of conditions was "the ventilator could fail when the altitude adjustment feature was set on 0 meters and the total flow volume was set at a delivery rate of less than 2.2 liters per minute. ${ }^{15}$

Only three of 109 failures indicated that more than two conditions were required to cause the failure. The most complex of these involved four conditions and was presented as "the error can occur when demand dose has been given, 31 days have elapsed, pump time hasn't been changed, and battery is charged." The remaining 233 failures did not contain sufficient detail to make a judgement on the number of test conditions required to demonstrate a fault; many described the cause as simply "software error." It is significant however, that of the 109 reports that are detailed, $98 \%$ showed that the problem could have been detected by testing the device with all pairs of parameter settings.

Medical devices generally have a relatively small number of input variables, each with either a small discrete set of possible settings, or a finite range of values. Nevertheless, testing all possible combinations of settings may not be practical. For example, consider a device that has 20 inputs, each with 10 settings, for a total of $10^{20}$ combinations of settings. The few hundred test cases that can be built under most development budgets will of course cover less than a tiny fraction of a percent of the possible combinations. But the number of pairs of settings is in fact very small, and since each test case must have a value for each of the ten variables, more than one pair can be included in a single test case. Algorithms based on orthogonal latin squares are available that can generate test data for all pairs (or higher order combinations) at a reasonable cost. One such method makes it possible to cover all pairs of values for this example using only 180 test cases[9]]. This level of test effort should be practical for most devices in the categories reviewed in this report.

\footnotetext{
5 The policy of the National Institute of Standards and Technology is to use metric units of measurement in all its technical papers. In this document however, works of authors outside NIST are cited which describe measurement values in certain non-metric units, and it is not appropriate to provide converted values.
} 


\section{Lessons Learned}

The information about the software faults that caused these system failures provides valuable lessons and affirmation of quality practices appropriate for this domain. These concern development and maintenance procedures, assurance practices during development and maintenance activities, and testing or assurance strategies. For this domain, methods to prevent and detect faults should focus on logic and calculation errors. For logic, methods should address improved handling of various conditions, assumptions, and interactions among functions. Attention must be given to the details of calculations, such as verifying that the correct algorithm has been specified in the first place or that the programmed operators and increments are correct. The lessons addressed below are based on problems that were observed in this study, that is, they stood out as prevalent problems for this set of data and are related to the faults indicated in the fault tables in Section 3. Therefore the practices suggested in this report will likely vary in other domains. Studies of other domains may provide a variation of the lessons learned here along with a roadmap for selecting the best quality strategy within a company or domain from more general guidance on quality practices. Other guidance discussing general good practices in software development and assurance includes the Capability Maturity Model (CMM), and NIST documents on life cycle development and assurance, and verification and validation $[6,10,11]$.

\subsection{Development \& Maintenance}

While software development processes are well defined by such models as the CMM, this study indicates particular practices that would help prevent the faults that led to these specific failures. For example, training about features of the computer on which the device will reside might have prevented some computation errors concerning registers. Training in the application domain might have enhanced the developers' understanding of system behavior and may have enabled prevention of some problems. For example, understanding how the outputs of functions interact and will be used by the operator might have prevented wrong interval size that produced unusable charts. Attention to details, that is, checking and verifying one's work as related to the specifications for that work, might have prevented several problems. A member of the software team with experience in the application domain may have caught several problems. Many logic faults stemmed from misunderstanding of how various functions interact, that is, under certain conditions, and in some cases, that they would interact at all. A traceability map, used regularly, can identify inconsistencies or incompleteness. The following list highlights some practices recommended for development and maintenance tasks:

- Complete specification of requirements, with emphasis on conditions and interactions of functions. Formal methods may be considered for highly complex systems.

- Traceability of the development artifacts: requirements to design (high, low levels) to code to user documentation and to all test documentation, especially location of source of faults. The analysis should be conducted forward and backward. 
- Traceability and configuration management of all changes to the product as result of any assurance activities.

- Software configuration management.

- $\quad$ Change impact analysis.

- Expertise in the application domain by at least one person involved with quality practices such as requirements analysis, inspections, testing.

- Daily attention to details of the current process, the mapping to results of the previous process, and personal reviews of one's work.

- Training.

\subsection{Assurance Practices}

The quality of software is the responsibility of everyone involved in its development. Practices listed above for development and maintenance are a few enabling factors in establishing an environment in which this responsibility is recognized. Other tasks fall into the category of quality assurance, but may be performed by the persons engaged in development of the software artifacts or by those separated organizationally under some quality assurance name. Every artifact of development processes needs to be scrutinized.

The list of techniques supporting this scrutiny is long and is published in many books and articles on software engineering [10,11]. Instead we focus on the few techniques whose value is indicated by the faults causing the failures of these devices. The inspection technique, as per Glass [8], can be perceived as a variety of techniques that examine artifacts, ranging from requirements to design to code to test cases. Such techniques may include code reading, formal inspection meetings, review by programmer using various analytic techniques, and focused inspections. Porter and Votta describe scenario-based inspections in which participants looked for certain classes of errors[12]. Having some knowledge of the prevalent classes of errors of the product they are examining may help the participants in conducting these types of inspections. By understanding the system's intended behavior, they may perform appropriate analyses looking for improper conditions and other incorrect actions. The following list summarizes these suggestions:

- Focused review, inspection of the artifact against the types of faults characteristic of the domain, and the vendor's history.

- Training in the application domain, specifically about the device and its intended behavior.

- Traceability analysis, especially focused on completeness.

- Mental execution of potentially troublesome locations (e.g., an algorithm, a loop, an interface).

- $\quad$ Code reading.

- Recording of fault information from the assurance activities and better usage of this information.

- $\quad$ Recording, during development and quality assurance activities, of the symptoms that indicated there are faults.

- Checklists, questions, methods designed to force those symptoms to manifest themselves. 
- Formal or informal proof of algorithm correctness.

- Use of simulation in complex situations where several interactions may occur, especially involving several components of the system.

\subsection{Testing}

Testing is part of the general quality practices, with unit, integration, and system testing all conducted. The failures in this study indicated specific test strategies might have been useful in detecting problems before the systems were delivered. In particular, nearly all could be detected by testing all pairs of input values, a test criterion that should be practical for most of the devices. Many failures were recognized by behavior of the system, for example, a part moved unexpectedly, or medication was provided at an incorrect rate. Most of these resulted from logic faults, so test cases in complex systems should attempt to drive these symptoms to appear. In some cases, the systems were updated versions, so previous test histories may also have been helpful. The list summarizes these points:

- Test cases aimed at manifesting prevalent symptoms observed by device operators.

- Test cases that cover all pairs of input values, and all three or four-way combinations where practical.

- Training in the application domain and specifically about the device's intended behavior.

- $\quad$ Stress testing.

- $\quad$ Change impact analysis and regression testing.

- $\quad$ SCM release of versions with evidence of change impact analysis, regression testing; validation of changes.

- Integration testing focused on interface values under varying conditions.

- System testing under various environmental circumstances, with some conditions, input data incorrect or different from expected environmental conditions.

- Recording of test results, with special recording of all failures and their resolution, by failure and symptom of the system, and by fault type of the software.

\section{Conclusions}

This study yielded information affirming use of quality practices and identifying approaches for using fault and failure information to improve development and assurance practices. The nature of several faults indicates that known practices may not be used at all or may be misused. An important conclusion is that the use of generally accepted quality practices, rather than use of a "silver bullet" is significant toward reduction of system failures. Questions remain for further research:

- If the practices were not used, what can be done to make them more readily usable?

- If the practices were used, why did they fail to prevent or detect the fault?

- What methods not yet generally accepted may help to prevent some faults and subsequent failures? 
The analysis in this study demonstrates that different application domains may have different prevalent fault classes and different characteristic failure symptoms. Suggestions for improvement of assurance practices include:

- $\quad$ gathering failure and fault data,

- understanding the types of faults that are prevalent for a specific domain, and,

- $\quad$ developing prevention and detection approaches specific to these.

The subject of this study, failures of medical devices, comes from a relatively young industry, often new to adding microprocessors to devices ${ }^{6}$ and moving into highly complex procedures. As experience grows with both software development and building complex software systems, the prevalent fault classes may change. In domains with a long history of software, the classes may also differ. In newer applications such as Electronic Commerce, which rely on newer technologies, operating systems, and languages, we would anticipate perhaps new fault classes for the domains as well as for the underlying software technologies. Data collection and analysis can help to identify the most prevalent faults and the areas where better methods are needed to prevent and detect them before system delivery.

This report has shown that valuable lessons can be learned from system failures involving software. Some lessons may apply specifically to the application domain of study while some apply universally. It is important to continue this research on failures of systems built with modern technologies in various domains. The authors may be contacted by anyone willing to supply data.

\section{Acknowledgments}

The authors are grateful to the Food and Drug Administration (FDA) for making the data available to us. Our analyses and conclusions do not reflect any analyses or conclusions by the FDA. We appreciate the reviews and suggestions of Dr. Larry Reeker and the efforts of Mark Zimmerman and Michael Koo for their technical support.

\section{References}

[1] Petroski, Henry, To Engineer Is Human, Vintage Books of Random House, Inc., New York, 1992.

[2] [Kuhn] Kuhn, D.R., "Sources of Failure in the Public Switched Telephone Network," Computer Vol. 30, No. 4 (April, 1997).

[3] Gibbs, W., "Software's Chronic Crisis," Sci. Am. (Int.Ed.) 271, 3 (Sept.1994), 72-81.

${ }^{6} \mathrm{~A}$ medical device manufacturer adding software to a device for the first time called one author during preparation of this report. 
[4] Beizer, Boris, Software Testing Techniques, International Thomson Computer Press, 1990.

[5] IEEE Std 1044-1993, IEEE Standard for Classification for Software Anomalies, IEEE Standards Software Engineering Volume Four Resource and Technique Standards, The Institute of Electrical and Electronics Engineers, Inc., 1999, isbn 0-7381-1562-2.

[6] Paulk, et al., "Capability Maturity Model, Version 1.1," IEEE Software, July 1993, pp. 18-27.

[7] Fagan, M.E., "Design and Code Inspections to Reduce Errors in Program Development," IBM Systems Journal, Volume 15, number 3, 1976, pp. 219-248.

[8] Glass, Robert L., "Inspections -- Some Surprising Findings," Communications of the $A C M$, April 1999-Volume 42, Number 4, pp. 17- 19.

[9] Cohen, D.M., S.R. Dalal, M.L. Friedman, and G.C. Patton, "The AETG System: an Approach to Testing Based on Combinatorial Design. IEEE Trans. S. E. vol. 23, no. 7, 437-443, July, 1997.

[10] Wallace, Dolores R. and Laura M. Ippolito, "A Framework for the Development and Assurance of High Integrity Software," NIST SP 500-223, December, 1994, National Institute of Standards and Technology, Gaithersburg, MD 20899. http://hissa.nist.gov/publications/sp223/

[11] Wallace, Dolores R., Laura Ippolito, and Barbara Cuthill, "Reference Information for the Software Verification and Validation Process," NIST SP 500-234, National Institute of Standards and Technology, Gaithersburg, MD 20899, April 1996. http://hissa.nist.gov/VV234/

[12] Porter, A., et al., "An Experiment to Assess the Cost-Benefit of Code Inspections in Large Scale Software Developments," Proceedings of the Ninth Annual Software Engineering Workshop, National Aeronautics and Space Administration Goddard Space Flight Center, Greenbelt, MD 20771, December 1994. 

